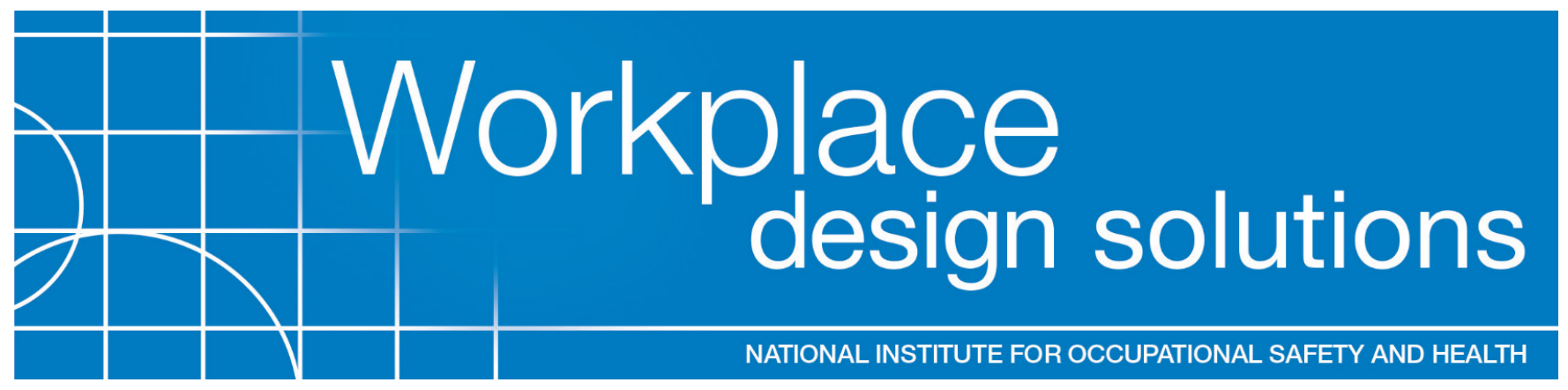

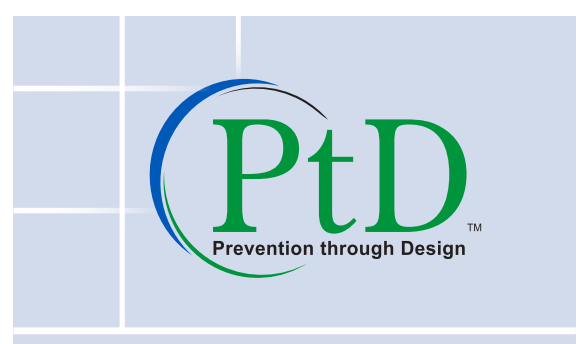

\section{Prevention through Design (PtD)}

Prevention through Design (PtD) can be defined as designing out or eliminating safety and health hazards associated with processes, structures, equipment, tools, or work organization. The National Institute for Occupational Safety and Health (NIOSH) launched a PtD initiative in 2007. The mission is to reduce or prevent occupational injuries, illnesses, and fatalities by considering hazard prevention in the design, re-design, and retrofit of new and existing workplaces, tools, equipment, and work processes [NIOSH 2008a,b].
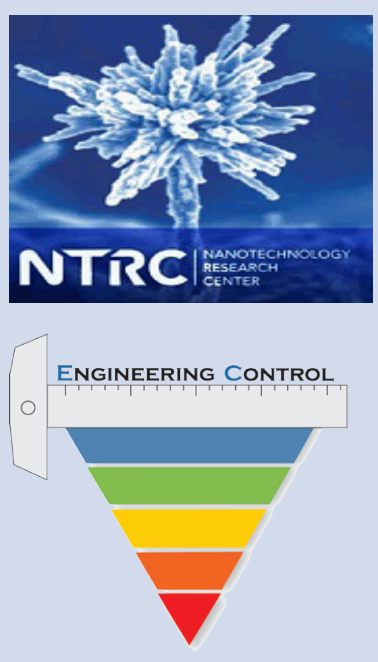

\title{
Protecting Workers during the Handling of Nanomaterials
}

\section{Summary}

Engineered nanomaterials (ENMs) are materials that are intentionally produced to have at least one primary dimension less than 100 nanometers $(\mathrm{nm})$. These materials have new or unique properties different from those of larger forms of the same material, making them desirable for specific product applications. The health effects associated with nanomaterials are not yet clearly understood, so it is important for producers and users of ENMs to reduce employee exposure and manage risks appropriately. In 2013, the National Institute for Occupational Safety and Health (NIOSH) published a compendium of control approaches for nanomaterial production and use processes entitled Current Strategies for Engineering Controls in Nanomaterial Production and Downstream Handling Processes. This Workplace Design Solutions document provides guidance on exposure control options for protecting workers during the handling of nanomaterials.

\section{Background}

The toxicity of many nanomaterials is presently unknown, but initial research indicates that there may be health concerns related to occupational inhalation exposures. Only a few types of ENMs have undergone extensive toxicological evaluation by NIOSH, e.g., titanium dioxide $\left(\mathrm{TiO}_{2}\right)$ and carbon nanotubes (CNTs). Results from animal studies with $\mathrm{TiO}_{2}$ and other poorly-soluble, low-toxicity particles of fine and ultrafine (nanoscale) sizes have shown adverse pulmonary responses in exposed rats, including persistent pulmonary inflammation and lung tumors [NIOSH 2011; Oberdörster 2002; Donaldson 2009; Poland et al. 2012]. Similar toxicological responses have also been observed in rats and mice exposed to CNTs and carbon nanofibers (CNFs) [NIOSH 2013a]. Because of the potential for adverse human health effects, it is important to control worker exposure and to manage risks appropriately throughout the lifecycle of ENM production.

\section{Description of Exposure}

Small-scale handling of nanopowders is a common task; examples include working with a quality assurance/control sample, weighing out a specific quantity for mixing/compounding, and processing smaller quantities in downstream industries. The tasks 
of weighing out nanomaterials can lead to worker exposure primarily through the scooping, pouring, and dumping of these materials. Dahm et al. [2012] conducted exposure assessments at six manufacturers and users of carbon nanotubes and nanofibers. This study showed that the highest exposures occurred during dry powder handling tasks including mixing and weighing operations. Many different types of commercially available enclosures can be employed to reduce exposure during the handling of nanopowders. The controls described below include chemical fume hoods, nanomaterial handling enclosures, biological safety cabinets [BSCs], and glovebox/isolators. This document provides information about hood and laboratory design and operation, administrative controls (such as good work practices), and the use of personal protective equipment.

NIOSH recommends that manufacturers and downstream users of nanomaterials develop PtD strategies to protect workers during the handling of engineered nanomaterials. Engineering controls protect workers by removing hazardous conditions or placing a barrier between the worker and the hazard, and along with good material handling techniques, they are likely to be the most effective control strategy for nanomaterials. The identification and adoption of effective control technologies is an important first step in reducing the risk associated with worker exposure to ENMs and ENM-associated byproducts.

\section{Engineering Controls}

A primary engineering control used in the nanotechnology industry during the handling, weighing, mixing, or sonication of engineered nanomaterials is a ventilated enclosure. These enclosures include fume hoods, nanomaterial handling enclosures, glove box/isolators, and biological safety cabinets (BSC) [NIOSH 2013b]. In addition, Bag In/Bag Out filter change out systems can help protect workers when removing filters contaminated with nanomaterials. Each of these controls should be carefully designed and properly operated to be effective. Many of the recommendations below have been compiled from documents by NIOSH and professional organizations [ANSI/AIHA 2012; NIOSH 2012, 2013b; NRC 2011].

\section{Design and Operational Considerations}

The following should be considered during the design and installation process for ventilated enclosures, such as fume hoods, nanomaterial handling enclosures and BSCs.

Consult a qualified industrial ventilation engineer, industrial hygienist, or containment specialist to design the new control system.

Locate the ventilated enclosure away from doors, aisles, walkways, and room air supply registers. Locate the hood a minimum of 5 feet from any HVAC air supply grille; a distance of 10 feet is preferred [NIOSH 2012].

Avoid air currents that are $30 \%-50 \%$ of the hood face velocity (typically between $30-50$ feet per minute [fpm]) as these tend to reduce containment efficiency [NRC 2011]. Check for an air face velocity between 80 and $100 \mathrm{fpm}$ into the chemical fume hood. For higher toxicity materials, a higher face velocity (between 100-120 fpm) may provide better protection. However, face velocities exceeding $150 \mathrm{fpm}$ may not improve performance and may increase hood leakage.

Newer nanomaterial handling enclosures may provide adequate containment at lower face velocities [NRC 2011]. These hoods are often based on ventilated balance enclosures used for potent powder handling in pharmaceutical applications and typically operate at an average face velocity between $65-85 \mathrm{fpm}$.

Ensure that each enclosure has an airflow indicator to show that it is working properly. This may include a flow indicator, flow alarm, or face velocity alarm that alerts users to improper exhaust flow.

Keep exhaust ducts short and simple - avoid flexible duct if possible. The duct material and filters chosen need to be compatible with the ENMs and byproducts generated.

Consider using Bag In/Bag Out filter change out systems to reduce the risk of exposure to maintenance personnel.

Ensure good lighting so workers are able to see well and possibly notice dust escaping.

Conduct initial performance tests of the control as installed at the facility. Use tracer gas tests described in consensus standards to evaluate containment effectiveness [ASHRAE 1995]. These tests should be scheduled as part of a regular preventive maintenance program to ensure adequate containment.

Use of nanopowders that are pre-mixed in a liquid may reduce the potential for airborne exposure if they are compatible with the process.

Restrict access to only those workers required to be in the work area.

Post appropriate warnings, including how to protect workers and visitors from exposure risks.

\section{Preventive Maintenance and System Checks}

Develop a written preventive maintenance (PM) plan to check system performance and repair identified deficiencies.

Keep equipment in effective and efficient working order. Review the enclosure manufacturer's performance specification to know whether the control is working properly. 
Look for signs of damage to the ducting and enclosure. Repair damage immediately.

$\square$ Regularly check that the enclosure system and the airflow indicator work properly and that the enclosure has no visible dust leaks.

Have a qualified industrial ventilation engineer or industrial hygienist examine the ventilated enclosure system and check its performance at least once every year or if it is modified or relocated.

At least annually, measure hood face velocity using procedures such as those detailed by consensus organizations (ACGIH, ASHRAE, ANSI), check airflows using smoke tracers, and verify the accuracy of installed flow monitoring devices such as face velocity monitors [ACGIH 2016; ANSI/AIHA 2012; ASHRAE 2011]. Keep this information in a PM logbook.

Conduct routine industrial hygiene monitoring to ensure controls are working at design conditions.

The figures below show the different engineering controls and what should be known about each as well as the limitations of their use.

\section{Chemical Fume Hood}

- Common control used in many settings, including with nanomaterials.

- Effectively contains nanomaterials for a range of activities.

- Should include design features such as airfoils at all edges and baffles inside the unit to reduce turbulence and improve containment.

- Older versions with constant airflow were found to leak even at the design face velocity [Tsai et al. 2009].

- Exhausts directly out of facility—not recirculated into workplace.

- Larger size, higher and potentially disruptive airflows compared with the nanomaterial handling enclosure.

- Higher energy costs for both fan motor and tempered replacement air than for low flow units such as the nanomaterial handling enclosure.

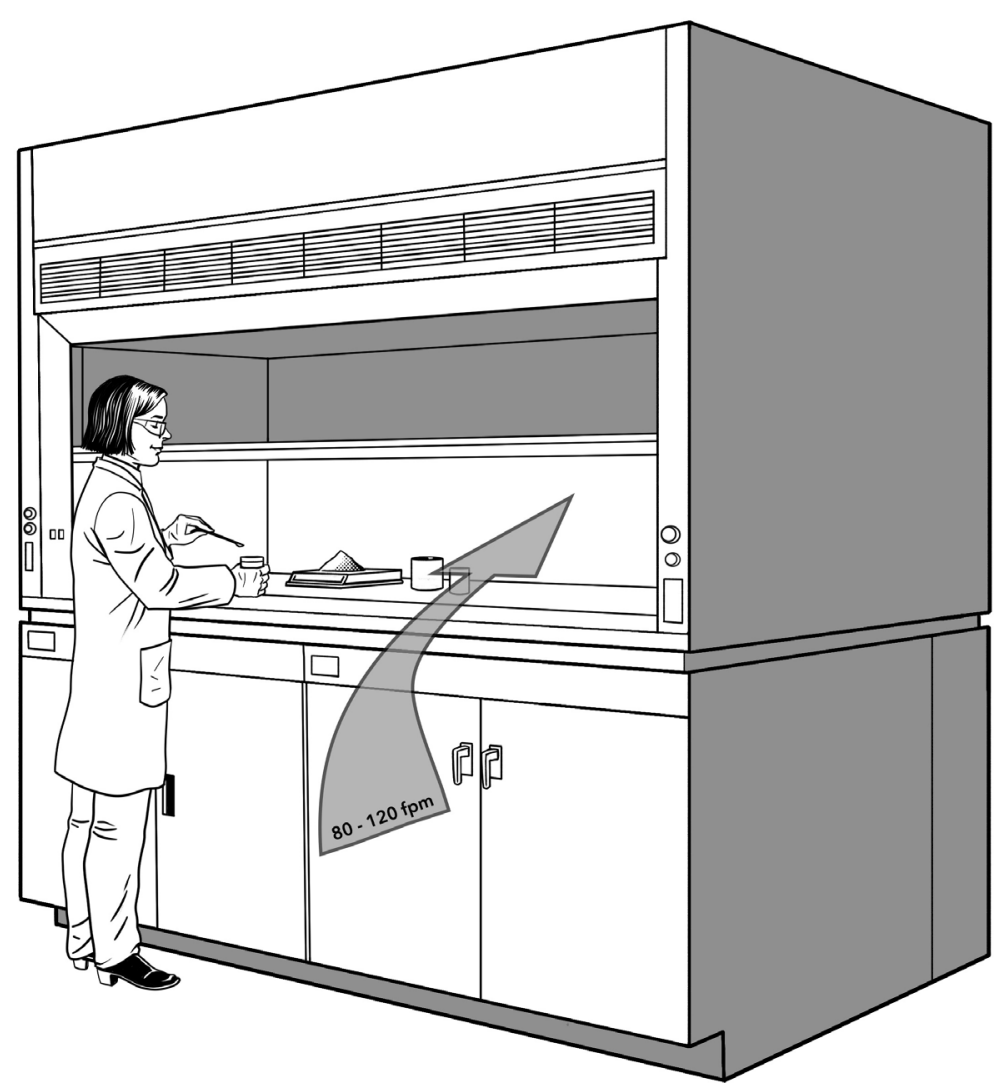




\section{Nanomaterial Handling Enclosure}

- Similar to pharmaceutical ventilated balance enclosures.

- Molded airfoils at edges, sill, and sash reduce turbulence.

- Some enclosures recirculate HEPA-filtered exhaust flows back into lab.

- Recirculating hoods are not appropriate for work with hazardous chemicals, such as solvents, which are not removed by HEPA filters.

- Consider using units with improved features such as Bag In/Bag Out exhaust filters and waste disposal chutes for better containment.

- Generally smaller and lower flow than chemical fume hoods.

- Provide improved environment for weighing/ handling nanomaterials.

- Protection may be compromised by airflow disturbances due to poor lab design/layout.

- Reduced energy usage due to lower airflow.

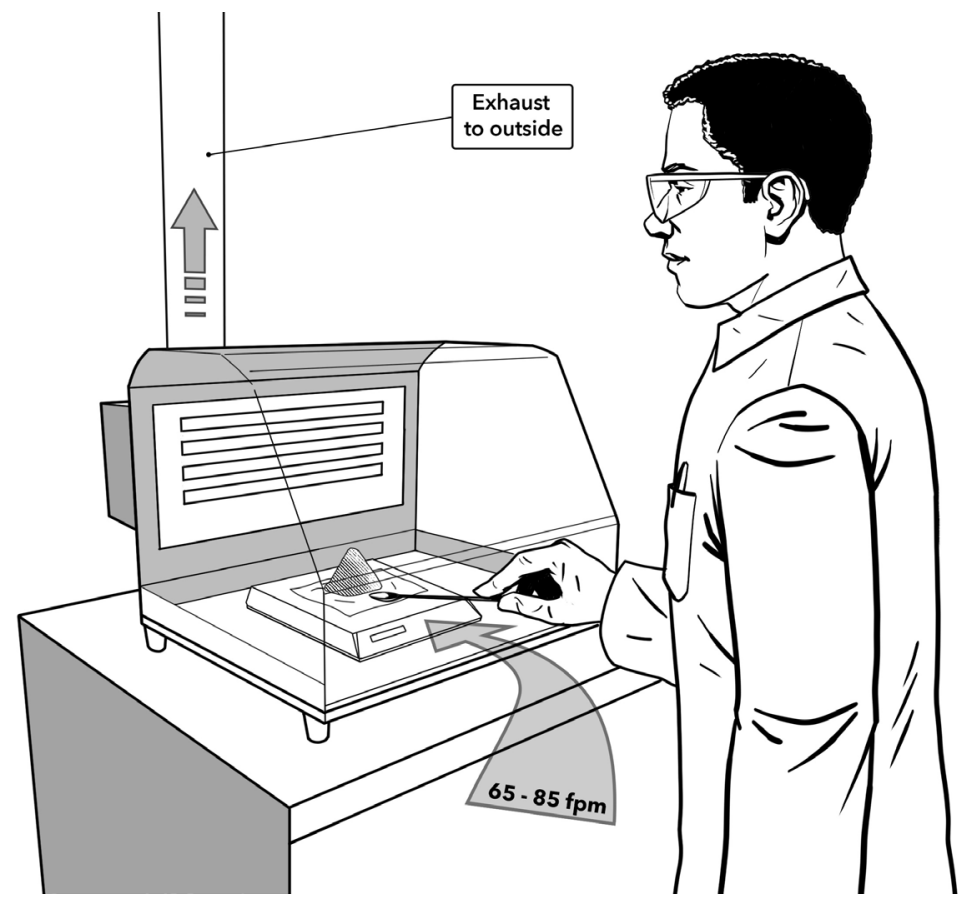

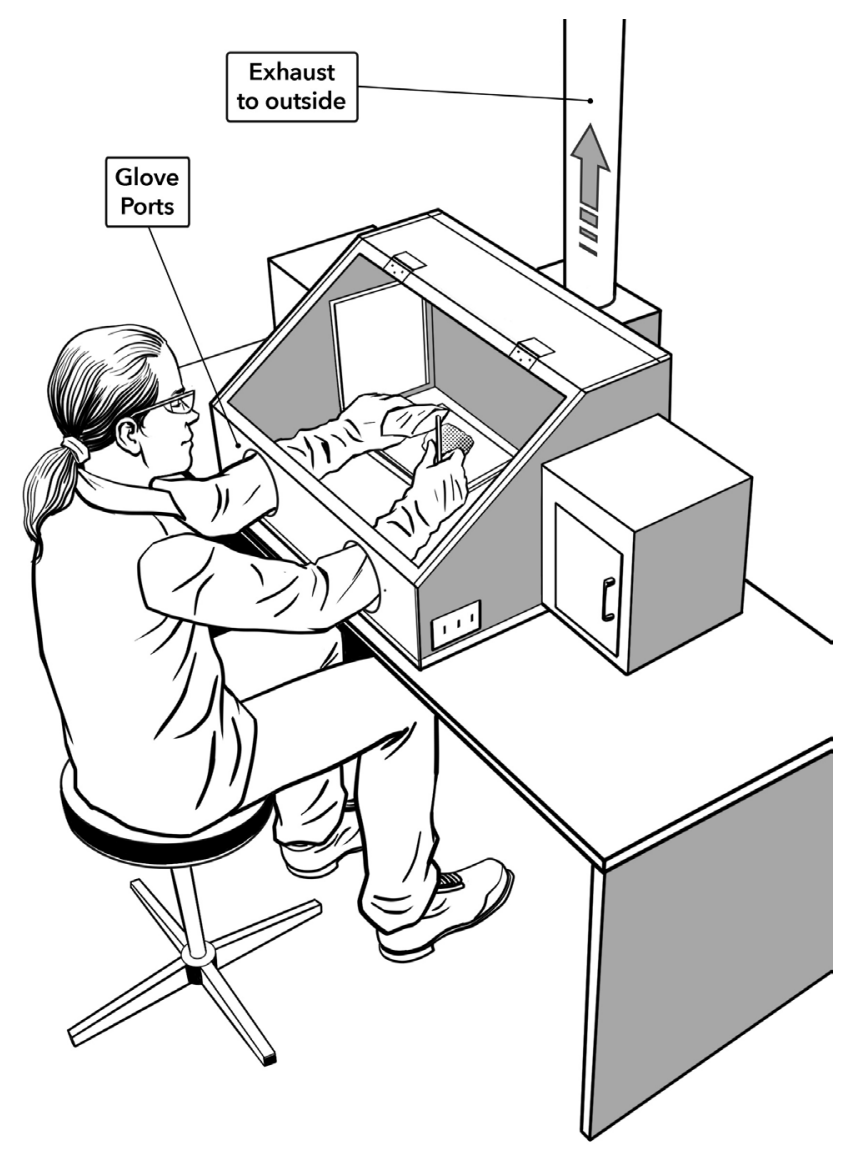

\section{Glovebox//solator}

- Highest level of protection for working with nanomaterials or other hazardous chemicals. Guidance on design, testing, and maintenance of these units is available [AGS 2007].

- Gloveboxes should be maintained at negative pressure so leaks are into the box rather than out of the box.

- These devices may be awkward to use due to restricted arm movements and difficulty seeing the process clearly. Consider using a mockup to assess ergonomic design prior to purchase.

- Conduct tests to verify that unit is operating as designed. Units require periodic inspection to check for tears in gloves and leaks.

- Energy costs are generally lower than other controls discussed here since very little exhaust flow is required to maintain negative pressure. 


\section{Biological Safety Cabinet (BSC)}

- Primary use is working with biological aerosols.

- There are several different types of BSCs, so care must be taken to understand the suitability of the hood for providing personnel protection when handling nanomaterials.

- The most common BSC, a Class II hood, protects both worker and product by containing the work while providing clean air to work surface.

- BSCs may recirculate HEPA-filtered air to work room and/or exhaust directly to outside.

- Recirculating hoods are not appropriate for work with hazardous chemicals, such as solvents, which are not removed by HEPA filters.

- Canopy connections (BSC Class II Type A2) are preferred for BSCs that exhaust to the outside.

- The downward air flow toward the work surface may make BSCs problematic when working with powdered nanomaterials.

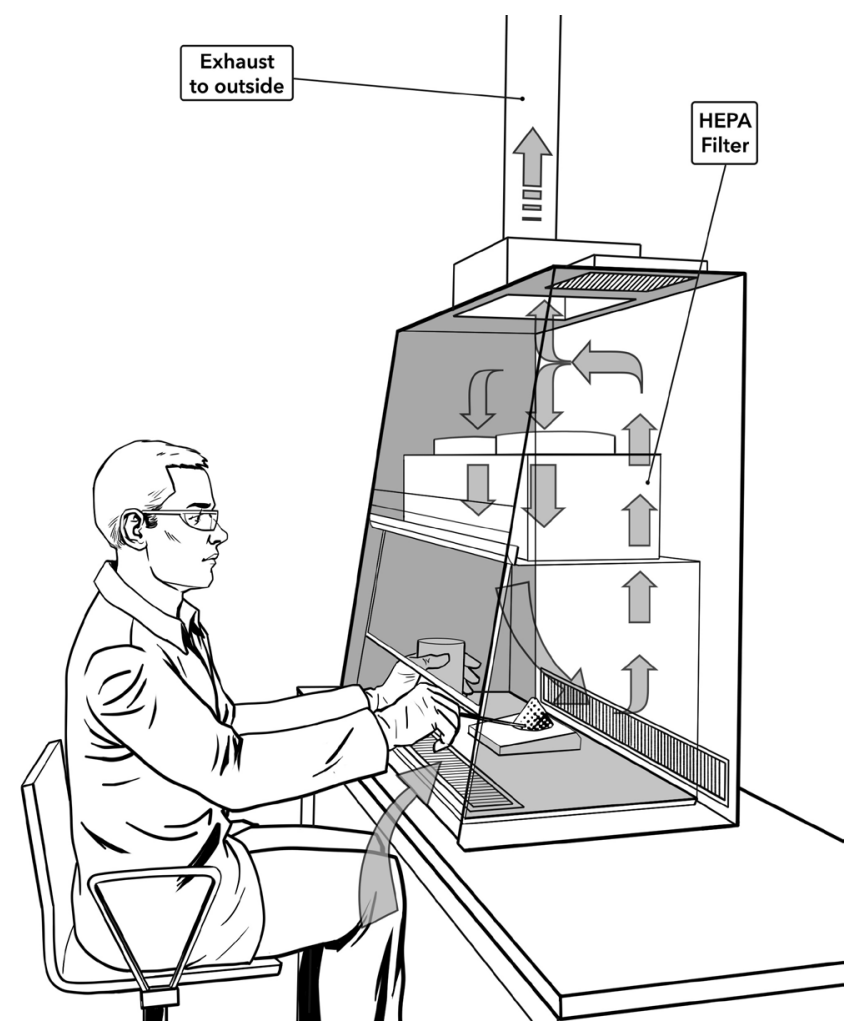

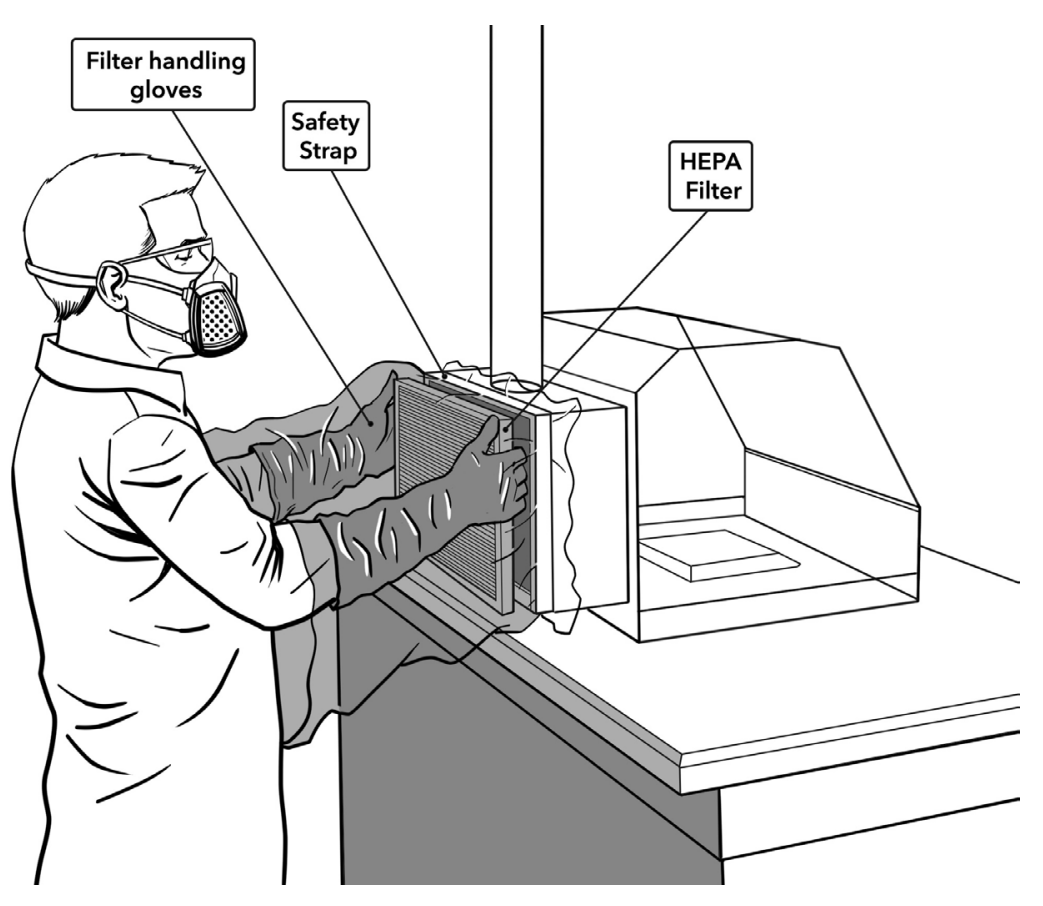

\section{Bag In/Bag Out Filter} Change Out

- Allows for removal of a dirty air filter while minimizing worker exposure.

- The containment bags often have integral gloves to make removing filter easier.

- A filter containment bag is attached to a service port on the unit by a safety strap.

- Bags with contaminated filters are cinched, closed using a double crimp/cut procedure, and disposed of properly.

- This process contains the filter with its contaminants so the worker is not exposed, and the particulates are not resuspended in the workplace environment. 


\section{Administrative Controls}

The use of engineering controls is likely the most effective control strategy for exposure to nanomaterials. Administrative controls and personal protective equipment (PPE) also have a place in PtD strategies and are usually identified as additional safeguards. Work practices, an administrative control, are procedures followed by employers and workers to control hazards in the workplace. These include housekeeping and cleaning, storage and use procedures, labels and postings, hazard training, and procedures for the use of engineering controls, many of which are discussed below. In addition, respirators may be needed and are often used during the implementation of engineering controls and work practices as well as during some short-duration maintenance procedures, and in emergencies. Therefore, facilities should consider the following administrative and PPE approaches as a part of a comprehensive occupational safety and health management plan for nanomaterial production and use.

\section{Good work practices}

For laboratory fume hood use, ensure that the sash is set at the certification mark for proper hood face velocity. Ensure that the sash is lowered and between the worker and the nanomaterial.

Avoid opening and closing the sash quickly and minimize rapid arm movements to reduce material leakage.

Place materials and equipment as far back in the hood as practical (at least six inches) without blocking the back slots/baffles. Mark the work surface six inches from the hood face to reinforce good work practices.

For chemical fume hood use, do not overcrowd or block the exhaust slots in the back of the hood. Place larger objects and equipment on blocks or racks to allow airflow to more smoothly reach the exhaust section of the hood.

When possible, work with the nanomaterials at the center of the hood for best containment efficiency. Visual tools such as tracer smoke or dry ice in a small container of water can help verify good capture within the enclosure.

Keep all unnecessary equipment and glassware out of the hood and appropriately stored.

Clean work surfaces with appropriate techniques (wet wipes or HEPA vacuum) as needed throughout the day and at least at the end of each day or work shift.

Clean up spills of liquids containing nanomaterials using absorbent materials and dispose of cleaning materials and waste in accordance with hazardous waste procedures.

\section{Cleaning and Housekeeping}

Clean the work area and equipment every day. Deal with spills immediately according to written procedures and using appropriate PPE. Standard approaches for cleaning spills can be used for cleaning surfaces contaminated with dry powder nanomaterials. These include using HEPAfiltered vacuum cleaners, wiping up dry powders with damp cloths, or wetting the powder before wiping.

Dispose of cleaning wipes and other contaminated materials in a sealed bag to prevent release of the dried nanomaterial. Nanomaterial-contaminated waste, including cleaning materials, should be kept in a separate waste stream.

Do not use dry methods such as a brush, broom, or compressed air to clean up contaminated work surfaces.

Cover all containers when not in use. Dispose of empty containers safely.

\section{Training}

Provide safety and health training to workers, supervisors, and managers including information on proper use, maintenance, and inspection of the control.

Provide workers with sufficient information to allow them to understand the nature of potential workplace exposures, health risks, routes of exposure, and instructions for reporting health symptoms [OSHA 2012].

Ensure that training includes how to keep exposures low; how to check that the ventilated enclosure is working; how to use and care for PPE, including respirators; and what to do if something goes wrong.

\section{Personal Protective Equipment}

\section{Personal Protective Clothing}

Because some types of nanoparticles have been found to penetrate the skin, appropriate protective clothing should be worn. PPE should be required when engineering and/or administrative controls are not feasible or effective in reducing exposures or when controls are not feasible such as maintenance or response to a spill. Follow job hazard assessment procedures for determining the need for and selection of PPE [OSHA 2002; ACS 2015].

If appropriate, use nitrile or other chemically impervious gloves during handling and cleanup of nanomaterials. Gloves should be selected based on their effectiveness against the nanomaterial as well as any other chemicals being used. Gloves should be inspected before use and changed at least at the end of each shift and whenever they show visible signs of wear. Used gloves should be kept 
in a sealed plastic bag in the work area until they can be disposed of properly.

Never use compressed air or other high energy techniques such as brushing or shaking to remove dust from clothing.

\section{Respirators}

Employers should consult with an occupational safety and health professional to determine the respirator best suited for their specific application. Employers should always follow the Occupational Safety and Health Administration (OSHA) Respiratory Protection Standard (29 CFR 1910.134) if respiratory protection is used (www.osha.gov/SLTC/etools/respiratory/index.html). NIOSH guidance for selecting respirators is found at http://www.cdc.gov/ niosh/docs/2005-100/default.html [NIOSH 2004].

\section{Acknowledgments}

This document was prepared by Dr. Kevin H. Dunn, Ms. Jennifer Topmiller, and Ms. Trudi McCleery, NIOSH Division of Applied Research and Technology, and Mr. John J. Whalen, formerly with NIOSH. Mr. Eugene Smith (on contract with NIOSH) prepared the illustrations. The authors gratefully acknowledge the contributions of the following NIOSH personnel who assisted with the technical content and review of the document, including: Ms. Laura Hodson, Dr. Pengfei Gao, Mr. Kevin L. Dunn, and Dr. Mark Hoover. Special appreciation is expressed to the following who served as external peer and stakeholder reviewers, including Dr. Kwangseog Ahn, Ms. Theresa Lane, Ms. Pamela Greenley, and Mr. Gary Partington.

\section{Suggested Citation}

NIOSH [2018]. Protecting workers during the handling of nanomaterials. By Dunn KH, Topmiller JL, McCleery T, Whalen J. Cincinnati, OH: U.S. Department of Health and Human Services, Centers for Disease Control and Prevention, National Institute for Occupational Safety and $\mathrm{H}$ ealth, DHHS (NIOSH) Publication No. 2018-121. DOI: https://doi.org/10.26616/ NIOSHPUB2018121

\section{References}

ACGIH [2016]. Industrial ventilation: a manual of recommended practice for design. 29th Ed. Cincinnati, OH: American Conference of Governmental Industrial Hygienists.

ACS [2015]. Identifying and evaluating hazards in research laboratories. Washington, DC: America Chemical Society. https:/www.acs.org/content/dam/acsorg/about/governance/ committees/chemicalsafety/publications/identifying-and-evaluating-hazards-in-research-laboratories.pdf

AGS [2007]. Guideline for gloveboxes, 3rd Edition. AGS-G001.
Santa Rosa, CA: American Glovebox Society.

ANSI/AIHA [2012]. American National Standard for laboratory ventilation. Fairfax, VA: American Industrial Hygiene Association Publication No. ANSI Z9.5-2012.

ASHRAE [1995]. Method of testing performance of laboratory fume hoods. American Society of Heating, Refrigerating, and Air Conditioning Engineers.

Dahm MM, Evans DE, Schubauer-Berigan MK, Birch ME, Fernback JE [2012]. Occupational exposure assessment in carbon nanotube and nanofiber primary and secondary manufacturers. Ann Occup Hyg 56:542-556.

Donaldson K [2009]. The inhalation toxicology of p-aramid fibrils. Crit Rev Toxicol 39:487-500.

NIOSH [2004]. NIOSH respirator selection logic. Cincinnati, OH: U.S. Department of Health and Human Services, Centers for Disease Control and Prevention, National Institute for Occupational Safety and Health, DHHS (NIOSH) Publication No. 2005-100. https://www.cdc.gov/niosh/docs/2005-100/default.html NIOSH [2008a]. Prevention through design: introduction. By Howard J. J Safety Res 39:113. http://www.cdc.gov/niosh/topics/ptd/pdfs/Howard.pdf

NIOSH [2008b]. National prevention through design (PtD) initiative. By Schulte P, Rinehart R, Okun A, Geraci C, Heidel D. http://www.cdc.gov/niosh/topics/ptd/pdfs/Schulte.pdf

NIOSH [2011]. Current intelligence bulletin 63: occupational exposure to titanium dioxide. Cincinnati, OH: U.S. Department of Health and Human Services, Centers for Disease Control and Prevention, National Institute for Occupational Safety and Health, DHHS (NIOSH) Publication No. 2011160. http://www.cdc.gov/niosh/docs/2011-160/

NIOSH [2012]. General safe practices for working with engineered nanomaterials in research laboratories. Cincinnati, OH: U.S. Department of Health and Human Services, Centers for Disease Control and Prevention, National Institute for Occupational Safety and Health, DHHS (NIOSH) Publication No. 2012-147. http://www.cdc.gov/niosh/docs/2012-147/

NIOSH [2013a]. Current intelligence bulletin 65: occupational exposure to carbon nanotubes and nanofibers. Cincinnati, OH: U.S. Department of Health and Human Services, Centers for Disease Control and Prevention, National Institute for Occupational Safety and Health, DHHS (NIOSH) Publication No. 2013-145. http://www.cdc.gov/ niosh/docs/2013-145/

NIOSH [2013b]. Current strategies for engineering controls in nanomaterial production and downstream handling processes. By Topmiller JL, Dunn KH. Cincinnati, OH: U.S. Department of Health and Human Services, Centers for Disease Control and Prevention, National Institute for Occupational Safety and Health, DHHS (NIOSH) Publication No. 2014102. http://www.cdc.gov/niosh/docs/2014-102/ 
NRC [2011]. Prudent practices in the laboratory: handling and management of chemical hazards, updated version. Washington, DC: The National Academic Press, National Research Council.

Oberdörster G [2002]. Toxicokinetics and effects of fibrous and nonfibrous particles. Inhal Toxicol 14:29-56.

OSHA [2002]. Job hazard analysis. Washington, DC: U.S. Department of Labor, Occupational Safety and Health Administration. Publication No. 3071 (Revised). https:// www.osha.gov/Publications/osha3071.pdf
OSHA [2012]. Hazard Communication (29 CFR 1910.1200). https://www.osha.gov/pls/oshaweb/owadisp. showdocument?p_table=standards\&p_id=10099.

Poland CA, Byrne F, Cho W, Prna-Mello A, Murphy FA, Davies GL, Coey J, Gounko Y, Duffin R, Volkov Y [2012]. Length-dependent pathogenic effects of nickel nanowires in the lungs and the peritoneal cavity. Nanotoxicol 6:899-911.

Tsai SJ, Ada E, Issacs JA, Ellenbecker MJ [2009]. Airborne nanoparticle exposures associated with the manual handling of nanoalumina and nanosilver in fume hoods J Nanopart Res 11:147-161.

\section{For More Information}

NIOSH developed detailed information about comprehensive PtD strategies for nanomaterial use and production [NIOSH 2013b] that can be found in the document Current Strategies for Engineering Controls in Nanomaterial Production and Downstream Handling Processes (http:// www.cdc.gov/niosh/docs/2014-102/pdfs/2014-102.pdf).

The information in this document is based on research related to Prevention through Design (PtD) initiatives. More information about $\mathrm{PtD}$ is available on the NIOSH website at http://www.cdc.gov/niosh/topics/PtD/

The Nanotechnology Research Center (NTRC) leads the federal government nanotechnology initiative to conduct research and provide guidance on the occupational safety and health implications and applications of nanotechnology. More information about the NTRC is available on the NIOSH website at https://www.cdc.gov/niosh/topics/ nanotech/nanotechnology-research-center.html

Engineering controls protect workers by removing hazardous conditions or by placing a barrier between the worker and the hazard. More information about the Engineering Controls Program is available on the NIOSH website at https://www.cdc.gov/niosh/engcontrols/
To obtain information about other occupational safety and health topics, contact NIOSH at:

Telephone: 1-800-CDC-INFO (1-800-232-4636)

TTY: 1-888-232-6348 • CDC INFO: www.cdc.gov/info or visit the NIOSH website at www.cdc.gov/niosh

For a monthly update on news at NIOSH, subscribe to NIOSH eNews by visiting www.cdc.gov/niosh/eNews.

Mention of any company or product does not constitute endorsement by NIOSH. In addition, citations to websites external to NIOSH do not constitute NIOSH endorsement of the sponsoring organizations or their programs or products. Furthermore, NIOSH is not responsible for the content of these websites.

This document is in the public domain and may be freely copied or reprinted. NIOSH encourages all readers of the Workplace Design Solutions to make them available to all interested employers and workers.

As part of the Centers for Disease Control and Prevention, $\mathrm{NIOSH}$ is the Federal agency responsible for conducting research and making recommendations to prevent workrelated illness and injuries. 